\title{
HEPATOPROTECTIVE EFFECT OF MELATONIN ON PARACETAMOL INDUCED HEPATOTOXICITY IN ALBINO RATS
}

\author{
DEEPAK SHANKARAPPA ${ }^{1}$, LOURDU JAFRIN A ${ }^{2 *}$, JAYAPRIYA B ${ }^{3}$, MAHARANI B ${ }^{2}$ \\ ${ }^{1}$ Department of Pharmacology, Madurai medical college (previously), General Practitioner, Bengaluru, Karnataka, India. ${ }^{2}$ Department of \\ Pharmacology, Indira Gandhi Medical College and Research Institute, Pondicherry, India. ${ }^{3}$ Department of Pharmacology, Govt. Medical \\ College, Virudhunagar, Tamil Nadu, India. Email: hiwedz@gmail.com
}

Received: 20 June 2021, Revised and Accepted: 30 July 2021

ABSTRACT

Objective: Liver is the most important organ involved in the biotransformation of drugs and hence also a prime site for drug-induced liver injury (DILI). Among the hepatotoxic drugs, paracetamol which is commonly used is a major offender, leading to about $40 \%$ of DILI. N-acetyl cysteine is commonly used to manage paracetamol poisoning. However, it has its own disadvantages. This study has been designed to probe into the possibility of an alternative drug for paracetamol-induced hepatotoxicity. The objective is to study the hepatoprotective effect of melatonin on paracetamol-induced hepatotoxicity in albino rats.

Materials and Methods: After prior approval from the IAEC, 36 albino rats were divided into six groups of six each. Each group received distilled water, paracetamol, paracetamol+N-acetyl cysteine, paracetamol+melatonin, and paracetamol+melatonin+N-acetyl cysteine, respectively. The liver function tests and histopathology of the liver of all the groups were compared. One-way ANOVA and post hoc Dunnett's test were used.

Results: Melatonin alone and in combination with $\mathrm{N}$-acetyl cysteine is found to have significant hepatoprotective effect in paracetamol-induced acute liver injury.

Conclusion: The main reason for hepatotoxicity is depletion of glutathione which is essential for conjugating the toxic metabolite $\mathrm{N}$ acetyl-p- benzoquinonimine (NAPQI) and CYP2E1 is playing the vital role of being the rate limiting enzyme initiating the cascade of events leading to acetaminophen hepatotoxicity. This is postulated to be reversed by melatonin.

Keywords: Drug-induced liver injury, hepatotoxicity, paracetamol, N-acetyl cysteine, melatonin.

(C) 2021 The Authors. Published by Innovare Academic Sciences Pvt Ltd. This is an open access article under the CC BY license (http://creativecommons.org/ licenses/by/4.0/) DOI: http://dx.doi.org/10.22159/ajpcr.2021v14i9.42539. Journal homepage: https://innovareacademics.in/journals/index.php/ajpcr

\section{INTRODUCTION}

Drug-induced liver injury (DILl) is the leading cause of acute liver failure in the United States also due to under-reporting, the incidence of hepatotoxicity is largely underestimated in the general population [1]. More than $50 \%$ of acute hepatocellular injury is caused by DILl [2], which includes hepatotoxicity caused by an overdose of acetaminophen and idiosyncratic liver injury triggered by other drugs (13\%) [3].

Liver toxicity is the most common form of adverse drug reaction resulting in aborted drug development or withdrawal after licensing and is usually predictable with known drugs [4]. It has been postulated that to detect a single case of DILl (with 95\% confidence), the clinical study would require approximately 30,000 patients. As a result, hepatotoxicity of several drugs fails to be detected during clinical trials, as the number of patients involved in a clinical study rarely exceeds 5000. Furthermore, a better understanding of the underlying mechanism of DILl is imperative for the development of improved preclinical screening and effective clinical trials to evaluate hepatotoxic effects of drugs before its release into the pharmaceutical market [1].

Because of the significant patient morbidity and mortality associated with DILl, the U.S. Food and drug administration (FDA) has removed several drugs from the market, including Bromfenac, Ebrotidine, and Troglitazone. Other hepatotoxic drugs, such as Risperidone, Trovafloxacin, and Nefazodone, have been assigned "black box" warnings.

DILl represents an important diagnostic challenge for physicians, as it may mimic features of both acute and chronic liver disease. of particular concern is the acute presentation, which is often severe and life-threatening. Drugs account for more than $50 \%$ cases of acute liver failure, with acetaminophen accounting for the majority, according to an ongoing prospective study [5]. Acetaminophen toxicity produces the most common form of acute liver failure in the United States, accounting for $39 \%$ of cases

At present, $\mathrm{N}$-acetylcysteine is used as an antidote to paracetamol poisoning. The limitations with its use are fatal anaphylactoid reactions, dose-dependent hypotension, and bronchospasm. In addition, it should be started with in $8 \mathrm{~h}$ of poisoning. In view of all these shortcomings and paracetamol poisoning being one of the commonest one reported, the search for a better and safer antidote is always there. Hence, the present study is to find a better alternative treatment for acute paracetamolinduced hepatotoxicity.

Drug hepatoxicity can be nonidiosyncratic (predictable), as in the case of acetaminophen, or idiosyncratic (unpredictable) [6]. Idiosyncratic DILl accounts for $13 \%$ of cases of acute liver failure in the United States [7].

\section{MATERIALS AND METHODS}

Materials

Animals: 30 adult albino rats of either sex weighing 200-250 g.

Drugs: Tab. Paracetamol, Tab. N-acetylcysteine, Tab. Melatonin, distilled water, Inj. Ketamine.

Equipment: Infant feeding tube and Syringes (1 ml, $2 \mathrm{ml})$. 


\section{Methods}

Albino rats of Wistar strain with the weight of 200-250 g were used for this study. Animals were obtained from Central Animal House of Madurai Medical College, Madurai, inbred and grown under suitable laboratory conditions. The study was conducted with the approval of the Institutional Animal Ethical Committee (Ref. No:17956)

\section{Inclusion criteria}

The following criteria were included in the study:

- Body weight of 200-250 g.

- Rats previously unused for any other experiment.

\section{Exclusion criteria}

The following criteria were excluded from the study:

- Rats weighing more than $250 \mathrm{~g}$ and $<200 \mathrm{~g}$

- Pregnant female

- Thirty albino rats of either sex weighing 200-250 g were selected and randomly divided into five equal groups, each containing six rats.

\section{Normal control (C1)}

This group received distilled water ( $2 \mathrm{ml} /$ day) orally at 0,24 , and $48 \mathrm{~h}$

\section{Hepatotoxic control (C2)}

In this group, the acute hepatic injury was induced by single oral administration of paracetamol at a dose of $1.5 \mathrm{~g} / \mathrm{kg}$ body weight at $0 \mathrm{~h}$. of the experiment followed by distilled water orally at 24 and $48 \mathrm{~h}$.

\section{Standard group (S)}

In this group, rats received a single toxic dose of paracetamol $1.5 \mathrm{~g} /$ $\mathrm{kg}$ body weight orally followed by $\mathrm{N}$-acetylcysteine $650 \mathrm{mg} / \mathrm{kg}$ body weight orally at $0 \mathrm{~h}$ of the experiment followed by $\mathrm{N}$-acetylcysteine $325 \mathrm{mg} / \mathrm{kg}$ at 24 and $48 \mathrm{~h}$.

\section{Test group (T1)}

In this group, rats received a single toxic dose of paracetamol $1.5 \mathrm{~g} / \mathrm{kg}$ body weight orally followed by melatonin $100 \mathrm{mg} / \mathrm{kg}$ body weight orally at 0,24 , and $48 \mathrm{~h}$

\section{Test group (T2)}

In this group, rats received a single toxic dose of paracetamol $1.5 \mathrm{~g} / \mathrm{kg}$ body weight orally followed by a combination of $\mathrm{N}$-acetylcysteine $650 \mathrm{mg} / \mathrm{kg}$ bodyweight and melatonin $100 \mathrm{mg} / \mathrm{kg}$ body weight orally at $0 \mathrm{~h}$. combination of $\mathrm{N}$-acetylcysteine $325 \mathrm{mg} / \mathrm{kg}$ and melatonin $100 \mathrm{mg} / \mathrm{kg}$ at 24 and $48 \mathrm{~h}$. After $72 \mathrm{~h}$ of paracetamol administration, the animals were anesthetized using ketamine. Then, blood was withdrawn directly from heart and serum was separated by centrifugation for the study of biochemical parameters such as,

- Serum protein

- Serum bilirubin

- Aspartate aminotransferase (AST)

- Alanine aminotransferase (ALT)

Liver was removed en-mass after sacrificing the animal by carotid bleeding and preserved in 10\% formalin for histopathological studies.

\section{Statistical analysis}

One-way Analysis of Variance (ANOVA) was used for multiple group comparisons followed by Post hoc Dunnett's test for inter group comparison of biochemical parameters.

\section{RESULTS}

In the present study, thirty albino rats were selected and evaluated for the hepatoprotective activity of melatonin in paracetamol induced liver injury. Both biochemical parameters, namely, serum AST, ALT, bilirubin, and protein were estimated as well as the histopathological examination was done. Results were tabulated and analyzed using oneway ANOVA followed by post hoc Dunnett's test.
Biochemical parameters Normal control group (CI)

The normal control group (C1) rats level of serum AST, ALT, bilirubin, and protein of about $30.5 \pm 3.33 \mathrm{IU} / \mathrm{L}, 38.16 \pm 1.722 \mathrm{IU} / / \mathrm{L}$, $0.68 \pm 0.10 \mathrm{mg} / \mathrm{dl}$, and $7.367 \pm 0.4 \mathrm{~g} / \mathrm{dl}$, respectively (Table 1 )

\section{The hepatotoxic control group (C2)}

The hepatotoxic group (C2) rats showed a significant increase in values of serum AST, ALT, and bilirubin to $219 \pm 21.33 \mathrm{IU} / \mathrm{L}, 127 \pm 11.6 \mathrm{IU} / \mathrm{L}$, and $1.33 \pm 0.22 \mathrm{mg} / \mathrm{dl}$, respectively, and significant decrease in serum protein level to $5.9 \pm 0.237 \mathrm{~g} / \mathrm{dl}$ (Table 1 ) when compared to control group $(\mathrm{Cl})$

\section{Standard group (S)}

In rats in the third group (S), there was significant decrease in mean values of serum AST, ALT, and bilirubin to $55.8 \pm 6.62 \mathrm{IU} / \mathrm{L}$, $65.8 \pm 4.91 \mathrm{IU} / \mathrm{L}$, and $0.70 \pm 0.09$, respectively, and significant elevation of serum protein level to $6.6 \pm 0.26$ (Table 1), when compared to the paracetamol treated group.

\section{Test group 1 ( $\mathrm{Tl})$}

The test Group 1 (T1) showed significant decrease in values of serum AST, ALT, and bilirubin to $68.3 \pm 4.17 \mathrm{IU} / \mathrm{L}, 37.16 \pm 3.18 \mathrm{IU} / \mathrm{L}$, and $0.90 \pm 0.09 \mathrm{mg} / \mathrm{dl}$, respectively, and significant elevation of serum protein level to $7.05 \pm 0.18 \mathrm{~g} / \mathrm{dl}$ (Table 1 ), when compared to the group treated with paracetamol alone.

\section{Test group 2 (T2)}

The test Group 2 (T2) showed significant decrease in mean values of serum AST, ALT, and bilirubin to $62.33 \pm 2.42 \mathrm{IU} / \mathrm{L}, 39.00 \pm 4.33 \mathrm{IU} / \mathrm{L}$, and $0.7 \pm 0.08 \mathrm{mg} / \mathrm{dl}$, respectively, and significant elevation of serum protein level to $6.96 \pm 0.19 \mathrm{~g} / \mathrm{dl}$ (Table 1 ) when compared to the group treated with paracetamol.

The statistical analysis was done with one-way ANOVA test for intergroup comparison for each parameter followed by post hoc Dunnett's test for intragroup comparison

Comparison of mean values of serum protein showed statistically significant difference ${ }^{* * *}(\mathrm{p}<0.001)$ with $\mathrm{F}$ value of 21.51 . Serum protein in the groups which received melatonin $(\mathrm{Tl})$ and combination of N-acetylcysteine with melatonin (T2) did not differ as that of normal control group (C1), while melatonin (TI) and combination of $\mathrm{N}$-acetylcysteine with Melatonin (T2) were equally effective in improving serum protein. Rest of groups showed statistically significant difference.

Table 1: Effect of melatonin alone and as an adjunct to $\mathrm{N}$-acetyl cysteine in paracetamol induced hepatotoxicity in albino rats

\begin{tabular}{lllll}
\hline Parameters & $\begin{array}{l}\text { Serum } \\
\text { protein } \\
\text { (g/dl) }\end{array}$ & $\begin{array}{l}\text { Total } \\
\text { bilirubin } \\
\text { (mg/d) }\end{array}$ & $\begin{array}{l}\text { AST } \\
\text { (IU/l) }\end{array}$ & $\begin{array}{l}\text { ALT } \\
\text { (IU/l) }\end{array}$ \\
\hline $\begin{array}{l}\text { Groups (n=6) } \\
\text { Normal Control } \\
\text { (Cl)- distilled }\end{array}$ & $7.367 \pm 0.48$ & $0.68 \pm 0.10$ & $30.5 \pm 3.33$ & $38.16 \pm 1.72$ \\
$\begin{array}{l}\text { water } \\
\text { Hepatotoxic } \\
\text { Control (C2)- } \\
\text { paracetamol }\end{array}$ & $5.9 \pm 0.23$ & $1.33 \pm 0.22$ & $219 \pm 21.33$ & $127 \pm 11.6$ \\
$\begin{array}{l}\text { Standard (S)- N- } \\
\text { acetyl cysteine } \\
\text { Test Group (Tl)- } \\
\text { melatonin }\end{array}$ & $6.6 \pm 0.26$ & $0.70 \pm 0.09$ & $55.8 \pm 6.62$ & $65.8 \pm 4.91$ \\
$\begin{array}{l}\text { Test Group (T2)- } \\
\text { melatonin and } \\
\text { N-acetylcysteine }\end{array}$ & $6.96 \pm 0.20$ & $0.76 \pm 0.08$ & $62.33 \pm 2.42$ & $39 \pm 4.33$ \\
\hline $\begin{array}{l}\text { Values are expressed as mean } \pm \text { standard deviation; SD. Statistical significance } \\
\text { was calculated with ANOVA followed by Dunnett's test comparing the treated } \\
\text { group with the paracetamol group }\end{array}$ & & & \\
\hline
\end{tabular}


Comparison of mean values of serum bilirubin showed statistically significant difference ${ }^{* * *}(\mathrm{p}<0.001)$ with $\mathrm{F}$ value of 22.98 . The reduction in the serum bilirubin level in the group which received combination of $\mathrm{N}$-acetylcysteine and melatonin (T2) did not differ as that of the normal control (C1). The values in the groups which received melatonin (T1), $\mathrm{N}$-acetylcysteine $(\mathrm{S})$ was not statistically different. Rest showed statistical significance between the groups. Comparison of mean values of Serum AST showed statistically significant difference ${ }^{* * *}(\mathrm{p}<0.001)$ with $\mathrm{F}$ value 334. post hoc Dunnett's test showed significant difference in all groups

Comparison of mean values of serum ALT showed statistically significant difference ${ }^{* * *}(\mathrm{p}<0.001)$ with $\mathrm{F}$ value 255 . Melatonin $(\mathrm{Tl})$ reduced serum ALT level to almost normal level and both Melatonin and its combination with $\mathrm{N}$-acetylcysteine (T2) were equally effective in reducing serum ALT level. Rest of the groups showed statistically significant difference.

\section{Histopathological study}

Gross examination of rat liver from control group (C1) (Fig. 1) showed normal appearance, red color, smooth, and regular under surface without any evidence of hemorrhage and necrosis. Paracetamol treated group (C2) (Fig. 2) showed multiple areas of necrosis and massive hemorrhagic patches. Liver weight was also decreased in this group.

$\mathrm{N}$-acetylcysteine treated group (Fig. 3) the architecture of the liver was well maintained. Groups receiving melatonin (Tl) (Fig. 4) and combination of melatonin and $\mathrm{N}$-acetylcysteine groups (T2) (Fig. 5) liver showed near normal appearance of liver regarding color under surface and organ weight. Histology of liver from control group showed portal triad, rows of hepatocytes with normal arrangements of hepatocytes with nuclei. Paracetamol treated liver sections showed abundant centrilobular necrosis ( $3^{\text {rd }}$ and $2^{\text {nd }}$ zone), bridging type of necrosis, cloudy swelling, pyknotic nuclei, loss of ribosome, cytoplasmic matrix swelling, and eosinophilic cytoplasm. There were small lipid globules in surviving hepatocytes, congestion of central vein and sinusoids and gross prominent hydropic vacuolation. Histology of liver sections from treated rats revealed mild centrilobular hepatocytes degeneration, few areas of congestion with mild fatty changes, decrease in inflammation, and very scanty degeneration of hepatocytes without any necrotic changes.

\section{DISCUSSION}

Liver, the major drug metabolizing and detoxifying organ in the body, is subjected to potential damage by the pharmaceutical and
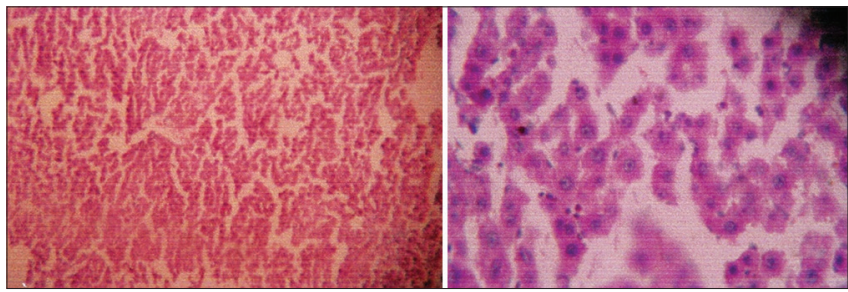

Fig. 1: Histology of control group (C1) rat liver showing normal architecture of hepatic lobule in LPF (10x) and HPF (40x)
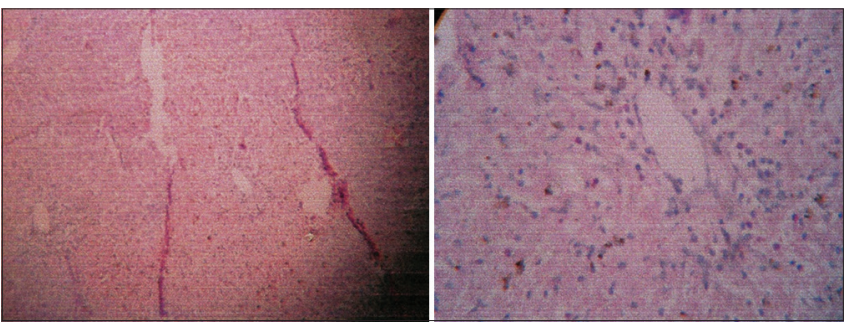

Fig. 2: Histology of PCM treated group (C2) rat liver showing intense centrilobular necrosis, bridging type of necrosis, congestion of sinusoids LPF (10x) and HPF (40x) environmental chemicals [8-10]. Many of the widely used therapeutic drugs, including over the counter drugs can cause hepatic injury. Of the numerous medicinal agents, chemicals, and herbal remedies in existence, more than 600 are recognized as being capable of producing hepatic injury [11].

Acetaminophen, the active metabolite of phenacetin, is one of the commonly used analgesic and antipyretic. The most serious acute adverse effect of over dosage of acetaminophen is a potentially fatal hepatic necrosis. Acetaminophen, as an example of a drug with dose related toxic effects, rapidly causes hepatocyte injury, predominantly in the centrilobular region [12-15]. It is well known that $\mathrm{N}$-acetylcysteine is widely used as hepatoprotective drug for acetaminophen toxicity, which acts by replenishing glutathione stores [16-18]. Due to its life threatening adverse effects such as anaphylactoid reaction, acute over dosage - bronchospasm, and hypotension, there is always a quest for identifying a better alternative to treat paracetamol toxicity. This study was undertaken to find the effectiveness of Melatonin, which is a cytochrome P450 2El down regulator [19].

From the results obtained it is observed that melatonin alone (T1) and its combination with $\mathrm{N}$-acetylcysteine (T2) provided statistically significant hepatoprotective effect when compared to $\mathrm{N}$-acetylcysteine (S) in acute paracetamol induced hepatotoxicity. The hepatoprotective outcome was evidenced by both histopathological study and biochemical parameters. There was marked reduction in centrilobular necrosis and congestion of liver on histopathological
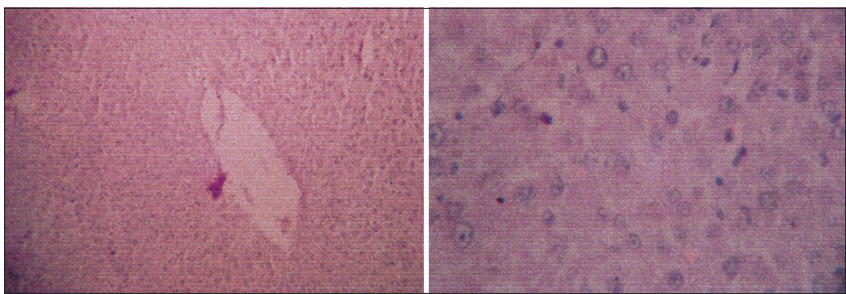

Fig. 3: Histology of nacetylcysteine treated rats (S) showing almost normal lobular architecture with mild centrilobular degeneration of hepatocytes and mild congestion in LPF and HPF $(40 \times)$

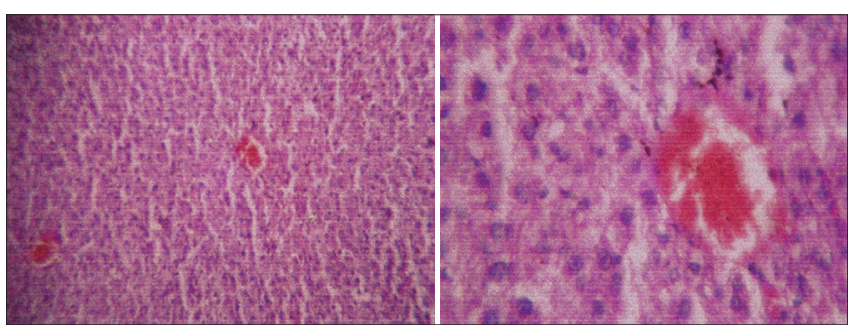

Fig. 4: Histology of melatonin and PCM treated group rats (T1) showing almost normal lobular architecture with very mild centrilobular degeneration of hepatocytes and mild congestion in LPF (10x) and HPF (40x)
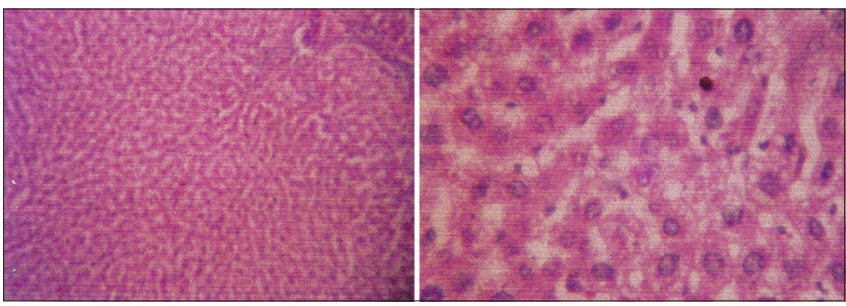

Fig. 5: Histology of melatonin, $n$ acetylcysteine and PCM treated group rats (T2) showing almost normal lobular architecture with very mild centrilobular degeneration of hepatocytes and mild congestion in LPF (10x) and HPF (40x) 
examination. There was statistically significant reduction in serum AST, ALT, bilirubin and elevation of serum protein levels in $\mathrm{Tl}$ and $\mathrm{T} 2$ when compared to $\mathrm{S}$.

Inter-comparison between $\mathrm{TI}$ and $\mathrm{T} 2$ revealed variable results. Both $\mathrm{T} 1$ and $\mathrm{T} 2$ were equally effective in improving serum protein and reducing serum ALT, While T2 reduced bilirubin better than Tl. Liver injury can be reflected by elevated transaminase alone or its combination with elevated bilirubin and decreased serum protein. It may be inferred that Melatonin (Tl) is at least as effective as when it is combined with $\mathrm{N}$ - acetyl cysteine (T'2) with respect to serum ALT and protein. Since combination therapy (T2) was more useful when bilirubin was taken in to account, it may be preferred in cases with elevated serum bilirubin in addition to elevated serum transaminases.

The main reason for hepatotoxicity is depletion of glutathione which is essential for conjugating the toxic metabolite $\mathrm{N}$ acetyl-pbenzoquinonimine (NAPQI) and CYP2E1 is playing the key role of being the rate limiting enzyme initiating the cascade of events leading to acetaminophen hepatotoxicity.

While Melatonin alone and/or its combination with N-acetylcysteine reverse the acetaminophen induced hepatic injury in experimental animals, the possible mechanism of inhibiting CYP2E1 is speculative and needs further evaluation. Furthermore, we need more human studies to arrive at a better alternative to the available antidote $\mathrm{N}$-acetylcysteine.

\section{CONCLUSION}

The present work is to assess the hepatoprotective activity of melatonin versus melatonin as an adjunct to $\mathrm{N}$-acetylcysteine, on paracetamol induced hepatotoxicity in albino rats, by comparison with hepatoprotective effect of $\mathrm{N}$-acetylcysteine. Thirty albino rats, following overnight fasting were divided into five groups with six animals each. Normal control (Cl), Hepatotoxicity control (C2), Standard (S), Test 1 (T1) and Test 2 (T2) which received distilled water, paracetamol alone, paracetamol and n-acetyl cysteine, paracetamol and melatonin, and paracetamol with melatonin and n-acetyl cysteine, respectively. The Hepatoprotective effect was assessed by the ability of the test group to produce statistically significant reduction in LFT biochemical parameters toward normal and in comparison with standard drug $\mathrm{N}$-acetylcysteine. This was further confirmed by doing histopathological studies.

The results of present study indicated Melatonin, melatonin, and its combination with $\mathrm{N}$-acetylcysteine provide hepatoprotective effect on paracetamol induced hepatotoxicity in rats, as evidenced by significant difference in biochemical parameters and histopathological study.

The efficacy and potency of hepatoprotective effect of melatonin, melatonin, and its combination with $\mathrm{N}$-acetylcysteine is better when compared to $\mathrm{N}$-acetylcysteine alone, as evidenced by significant difference in biochemical parameters and histopathological study.

Inter-comparison between melatonin, melatonin and its combination with $\mathrm{N}$-acetylcysteine revealed variable results. Melatonin alone could be better drug in comparison with $\mathrm{N}$-acetylcysteine, being more economical with better patient compliance and with no incidence of life threatening anaphylactoid reaction

Further studies are required to elucidate exact molecular and biochemical mechanisms involved and to establish its therapeutic role as hepatoprotective agents in humans.

\section{AUTHORS' CONTRIBUTIONS}

Dr. Deepak Shankarappa was involved in the planning and execution of the study. Dr. Lourdu Jafrin.A was involved in writing, reviewing of the Manuscript and also in execution of the study. Dr. Jayapriya.B was involved in editing of the manuscript, reference management and overall inputs. Dr. Maharani.B helped in correction of typographical and grammatical errors in the manuscript.

\section{CONFLICTS OF INTEREST}

The authors affirm no conflicts of interest, finance, or otherwise.

\section{AUTHORS' FUNDING}

No external funds were received for this research.

\section{REFERENCES}

1. Shapiro MA, Lewis JH. Causality assessment of drug-induced hepatotoxicity: Promises and pitfalls. Clin Liver Dis 2007;11:477-505.

2. Shen T, Liu Y, Shang J, Xie Q, Li J, Yan M, et al. Incidence and etiology of drug-induced liver injury in Mainland China. Gastroenterology 2019;156:2230-41.e11

3. Andrade RJ, Chalasani N, Björnsson ES, Suzuki A, Kullak-Ublick GA, Watkins PB, et al. Drug-induced liver injury. Nat Rev Dis Primers 2019;5:58

4. Lee WM. Drug-induced hepatotoxicity.N Engl J Med 2003;349:474-85.

5. Larson AM, Polson J, Fontana RJ, Davern TJ, Lalani E, Hynan LS, et al. Acetaminophen-induced acute liver failure: Results of a United States multicenter, prospective study. Hepatology 2005;42:1364-72.

6. Leise MD, Poterucha JJ, Talwalkar JA. Drug-induced liver injury. Mayo Clin Proc 2014;89:95-106.

7. Chalasani N, Fontana RJ, Bonkovsky HL, Watkins PB, Davern T, Serrano J, et al. Causes, clinical features, and outcomes from a prospective study of drug-induced liver injury in the United States. Gastroenterology 2008;135:1924-34, 1934.e1-4.

8. Ribeiro AJ, Yang X, Patel V, Madabushi R, Strauss DG. Liver microphysiological systems for predicting and evaluating drug effects. Clin Pharmacol Ther 2019;106:139-47.

9. Grant DM. Detoxification pathways in the liver.J Inherit Metab Dis 1991;14:421-30.

10. García-Suástegui WA, Ramos-Chávez LA, Rubio-Osornio M, CalvilloVelasco M, Atzin-Méndez JA, Guevara J, et al. The role of CYP2E1 in the drug metabolism or bioactivation in the brain. Oxid Med Cell Longev 2017;2017:4680732.

11. Ahmed OM, Fahim HI, Ahmed HY, Al-Muzafar HM, Ahmed RR, Amin KA, et al. The preventive effects and the mechanisms of action of navel orange peel hydroethanolic extract, Naringin, and Naringenin in $\mathrm{N}$-acetyl-p-aminophenol-induced liver injury in Wistar rats. Oxid Med Cell Longev 2019;2019:2745352.

12. Brune K, Renner B, Tiegs G. Acetaminophen/paracetamol:A history of errors, failures and false decisions. Eur J Pain 2015;19:953-65.

13. Gardner CR, Heck DE, Yang CS, Thomas PE, Zhang XJ, DeGeorge GL, et al. Role of nitric oxide in acetaminophen-induced hepatotoxicity in the rat. Hepatology 1998;27:748-54.

14. Walker RM, Racz WJ, McElligott TF. Acetaminophen-induced hepatotoxic congestion in mice. Hepatology 1985;5:233-40.

15. Laskin DL, Pilaro AM, Ji S. Potential role of activated macrophages in acetaminophen hepatotoxicity. II. Mechanism of macrophage accumulation and activation. Toxicol Appl Pharmacol 1986;86:216-26.

16. Atkuri KR, Mantovani JJ, Herzenberg LA, Herzenberg LA. N-Acetylcysteine-a safe antidote for cysteine/glutathione deficiency. Curr Opin Pharmacol 2007;7:355-9.

17. Hu J, Zhang Q, Ren X, Sun Z, Quan Q. Efficacy and safety of acetylcysteine in "non-acetaminophen" acute liver failure:A metaanalysis of prospective clinical trials. Clin Res Hepatol Gastroenterol 2015;39:594-9.

18. Rushworth GF, Megson IL. Existing and potential therapeutic uses for $\mathrm{N}$-acetylcysteine: The need for conversion to intracellular glutathione for antioxidant benefits. Pharmacol Ther 2014;141:150-9.

19. Liang YL, Zhang ZH, Liu XJ, Liu XQ, Tao L, Zhang YF, et al. Melatonin protects against apoptosis-inducing factor (AIF)-dependent cell death during acetaminophen-induced acute liver failure. PLoS One 2012;7:e51911. 